\title{
Knowledge, Attitude, and Practice of Diabetes Mellitus Among the Saudi Population in Riyadh, Saudi Arabia: A Quantitative Study
}

\author{
Muhammed Alqahtani $^{1}$, Faisal E. Almutairi ${ }^{2}$, Abdulrahman O. Albasseet ${ }^{3}$, Khalid E. Almutairi $^{2}$ \\ 1. Internal Medicine, Al-Imam Muhammad Ibn Saud Islamic University, Riyadh, SAU 2. Family Medicine, Al-Imam \\ Muhammad Ibn Saud Islamic University, Riyadh, SAU 3. Family Medicine, King Faisal Specialist Hospital \& Research \\ Centre, Riyadh, SAU
}

Corresponding author: Muhammed Alqahtani, algahtanimjk@gmail.com

\section{Abstract}

\section{Aim}

To investigate the knowledge, attitudes, and practices of diabetes among Saudi adults in Riyadh.

\section{Methods}

A questionnaire-based study was carried out in September 2019. A previously validated questionnaire was used to assess participants' knowledge.

\section{Results}

The study sample included 3,208 total participants. Of these, $53 \%$ were females and $47 \%$ were males. About $53.5 \%$ of the participants had good knowledge scores. The great majority of respondents did not know whether metformin could cause kidney damage $(n=2651,82.6 \%)$ and more than half did not know whether long-term drug use could cause organ failure $(n=2073,64.6 \%)$ and whether insulin could cause harmful effects ( $n=1836,57.2 \%)$. Results showed that $91.3 \%$ of the respondents stated that they would seek treatment if they or one of their family members got diabetes mellitus (DM). Approximately 50\% of the participants (49.9\%) regularly exercised. More than half (68\%) of the respondents had never checked their blood glucose levels on an annual basis. More than half of the respondents tried to avoid refined sugar.

\section{Conclusion}

The majority of the participants had never checked their blood glucose levels. In addition, one-third of the participants believed that the use of complementary medicine could actually control diabetes.

\section{Received 12/17/2019 \\ Review began 12/26/2019 Review ended 01/07/2020 Published 01/08/2020 \\ (c) Copyright 2020 \\ Alqahtani et al. This is an open access article distributed under the terms of the Creative Commons Attribution License CC-BY 3.0., which permits unrestricted use, distribution, and reproduction in any medium, provided the original author and source are credited.}

Categories: Family/General Practice, Medical Education, Public Health

Keywords: diabetes, awareness, attitude, practice

\section{Introduction}

The World Health Organization (WHO) has estimated that diabetes is considered the seventh cause of death, and it is well-known that diabetes mellitus (DM) is increasing rapidly worldwide [1]. Diabetes is a major burden on governments and individuals, as it plays a major role in renal failure, cardiac diseases, limb amputations, and blindness [1]. Saudi Arabia is reported to rank the second in the Middle East and the seventh worldwide in terms of the rate of diabetes. It is estimated that around seven million of the population are diabetic and almost around three million have pre-diabetes [2].

DM is defined as a group of metabolic disorders characterized by high blood glucose levels as a subsequence of defects in insulin secretion or action or possibly both [3]. Thus, understanding DM and its complications play a fundamental role in the management of the disease and, consequently, its local spread [4]. Patients with proper knowledge of diabetes and diabetes complications follow a suitable treatment and health care plan.

The aim of our study is to investigate the knowledge, attitudes, and practices of diabetes among Saudi adults to assess the general public's awareness of the disease and to draw the attention of the community to the burden of this disease.

\section{Materials And Methods}

This cross-sectional study was carried out in Riyadh, the capital and largest city in Saudi Arabia, in September 2019 among Saudi adults between the ages of 18 and 65 (population: 3,323,230). The link 
questionnaire was distributed through different social media platforms. The electronic link of this questionnaire contained consent of participation and ensured the privacy of the respondents. The Institutional Review Board (IRB) of our institution exempted our study from review.

We used a previously validated questionnaire [4] that was used to assess the knowledge, attitudes, and practices (KAP) regarding diabetes mellitus (DM) in Arabic. The first part of the survey included the demographics of the participants. Data included gender, age, level of education, average income, and occupation. Participants were also asked whether their occupation and education were related to the medical field.

Knowledge regarding DM was measured using eight main questions related to the risk factors, diagnosis, prevention, and complications of diabetes mellitus. The possible categorical answers were: "Yes," "Don’t know," and "No." The survey was scored as one point for each correct response and the total score was calculated out of 26. Participants were classified into three groups based on the cut-off values of 0-13, 14-18, and 19-26. These scores were used to define participants with poor, moderate, and good knowledge, respectively.

The diabetes attitude was assessed using seven questions related to compliance with the treatment of DM. The possible categorical answers were: "Yes," "Don’t know," and "No." Participants were given one point for each positive attitude and participants with four marks or more out of seven were considered as positive attitudes.

Practices toward DM were assessed using four questions. Answers were provided with three different categorical responses: "Yes," "No," and "Don’t know." "Yes" answers were considered positive practice, and "No" answers were considered negative practice.

Data were analyzed using R studio version 3.6.1. (RStudio, Inc.; Boston, MA, USA). Demographic data, such as gender, age, level of education, and income, were summarized using counts and percentages. Mean and standard deviation were used to summarize continuous data when appropriate. A univariate analysis was done using the t-test for continuous variables and chi-square for categorical variables. Binary logistic regression was done using backward logistic regression (LR). Variables were entered in the model if the univariate association was statistically significant at the 0.05 level. Variables were removed from the model if the p-value was greater than 0.1. Hypothesis testing was performed at the 0.05 level of significance.

\section{Results}

The study sample included a total of 3,208 participants. Of these, $53 \%$ were females and $47 \%$ were males. Participants aged $18-30,31-40$, and $41-60$ years represented $65.2 \%, 16.3 \%$, and $11.9 \%$ of the study sample, respectively. Only $8.32 \%$ had an occupation related to the medical field and $13.2 \%$ had a degree related to the medical field. Data are presented in Table 1. 


\section{Cureus}

\begin{tabular}{|c|c|}
\hline & $\mathrm{N}=3208$ \\
\hline \multicolumn{2}{|l|}{ Age: } \\
\hline$<18$ years & $182(5.67 \%)$ \\
\hline $18-30$ years & $2091(65.2 \%)$ \\
\hline 31 - 40 years & $524(16.3 \%)$ \\
\hline $41-60$ years & $381(11.9 \%)$ \\
\hline$>60$ years & $30(0.94 \%)$ \\
\hline \multicolumn{2}{|c|}{ Working in the medical field } \\
\hline No & 2941 (91.7\%) \\
\hline Yes & $267(8.32 \%)$ \\
\hline \multicolumn{2}{|l|}{ Gender: } \\
\hline Female & $1700(53.0 \%)$ \\
\hline Male & $1508(47.0 \%)$ \\
\hline \multicolumn{2}{|l|}{ Marital status: } \\
\hline Single & 2151 (67.1\%) \\
\hline Married & $982(30.6 \%)$ \\
\hline Divorced & $75(2.34 \%)$ \\
\hline \multicolumn{2}{|l|}{ Education: } \\
\hline Illiterate & $4(0.12 \%)$ \\
\hline Primary & $18(0.56 \%)$ \\
\hline Middle school & $62(1.93 \%)$ \\
\hline High school & $841(26.2 \%)$ \\
\hline Diploma & $348(10.8 \%)$ \\
\hline Bachelor & 1804 (56.2\%) \\
\hline Post-graduate & $131(4.08 \%)$ \\
\hline \multicolumn{2}{|c|}{ Education related to medical field: } \\
\hline No & $2784(86.8 \%)$ \\
\hline Yes & $424(13.2 \%)$ \\
\hline \multicolumn{2}{|l|}{ Monthly income: } \\
\hline$<2000$ SAR & $1479(46.1 \%)$ \\
\hline 2000 - 4000 SAR & $439(13.7 \%)$ \\
\hline 4000 - 10000 SAR & $538(16.8 \%)$ \\
\hline$>10000$ SAR & $752(23.4 \%)$ \\
\hline
\end{tabular}

TABLE 1: Demographic characteristics of the study sample

Knowledge was measured using eight questions related to disease diagnosis, risk factors prevention, and complications with a maximum possible knowledge score of 26 . The majority of the participants (86.8\%) knew that the dysfunction of the pancreas can lead to DM, 65.6\% were aware that blood sugar elevation occurs in DM, and approximately half of them (48.6\%) were aware that diabetes is not curable (Table 2). Regarding the diagnosis of DM, three-quarters of the participants were aware that fasting blood sugar is the 


\section{Cureus}

best way to diagnose DM. Responses also showed that participants were not aware of the role of urine testing for sugar.

\begin{tabular}{|c|c|}
\hline & $\mathrm{N}=3208$ \\
\hline \multicolumn{2}{|c|}{ Blood sugar in diabetics: } \\
\hline Decreases & $419(13.1 \%)$ \\
\hline Does not change & $72(2.24 \%)$ \\
\hline I don't know & $613(19.1 \%)$ \\
\hline Increases ${ }^{\star}$ & $2104(65.6 \%)$ \\
\hline \multicolumn{2}{|c|}{ DM is a dysfunction of: } \\
\hline Brain & $6(0.19 \%)$ \\
\hline I don't know & $275(8.57 \%)$ \\
\hline Kidneys & $89(2.77 \%)$ \\
\hline Liver & $47(1.47 \%)$ \\
\hline Lungs & $8(0.25 \%)$ \\
\hline Pancreas $^{\star}$ & $2783(86.8 \%)$ \\
\hline \multicolumn{2}{|c|}{ Diabetes is curable with treatment: } \\
\hline I don't know & $644(20.1 \%)$ \\
\hline $\mathrm{No}^{*}$ & $1560(48.6 \%)$ \\
\hline Yes & $1004(31.3 \%)$ \\
\hline \multicolumn{2}{|c|}{ Urine sugar is the best way to diagnosis DM } \\
\hline I don't know & $1187(37.0 \%)$ \\
\hline $\mathrm{No}^{*}$ & $1131(35.3 \%)$ \\
\hline Yes & $890(27.7 \%)$ \\
\hline \multicolumn{2}{|c|}{ Fasting blood sugar is the best way to diagnosis DM } \\
\hline I don't know & $591(18.4 \%)$ \\
\hline No & $211(6.58 \%)$ \\
\hline Yes $^{\star}$ & $2406(75.0 \%)$ \\
\hline
\end{tabular}

\section{TABLE 2: Participants' knowledge of the nature of DM}

DM: diabetes mellitus

Regarding the symptoms of DM, the most commonly reported symptoms were frequent urination (95.1\%), slow healing of wounds (88.4\%), and increased thirst (80.1\%). Regarding the complications of DM, kidney failure and heart attack were the most commonly chosen complications ( $53.6 \%$ and $55.4 \%$, respectively). The least chosen complication was hepatitis (28.3\%). And regarding the management of DM, $85.5 \%$ and $49.2 \%$ were aware that insulin injections and oral medications were effective for DM, respectively. The majority was aware of the role of avoiding sugary foods and regular exercise in the management of DM $(87.7 \%$ and $91 \%$, respectively). Only $54.4 \%$ were aware that the regular eating of herbs is not reliable for the management of DM.

The average knowledge score for participants was $15.7 \pm 3.98$. About $53.5 \%$ of the participants had good knowledge scores while approximately one-quarter of the participants $(n=893,27.8 \%)$ scored less than 14 , which corresponds to a poor level of knowledge. Moderate and good levels of knowledge were observed in $46 \%(n=1476)$ and $26.2 \%(n=839)$ of the respondents. 
The univariate association of socioeconomic factors with a good knowledge score ( $\geqslant 19$ ) was assessed using the chi-square test of independence. There was a statistically significant association between all socioeconomic factors included and having good knowledge regarding DM.

Males were more prevalent in the good knowledge group as compared to the poor/moderate group (54.5\% vs. $44.4 \%, \mathrm{P}<0.001)$. Participants older than 30 years were also more prevalent in the good knowledge group as compared to the poor/moderate group ( $48.2 \%$ vs. $22.4 \%$, respectively, $\mathrm{P}<0.00$ ). Participants working in the medical field were more prevalent in the good knowledge group as compared to the poor/moderate knowledge group (15.5\% vs. 5.78\%, respectively, $\mathrm{P}<0.001)$. There was a statistically significant association between marital status and having good knowledge $(\mathrm{P}<0.001)$, where married participants were more prevalent in the good knowledge group ( $48.5 \%$ vs. $24.3 \%$, respectively). Education showed a statistically significant association with having good knowledge. Respondents that received education related to the medical field were also more prevalent in the good knowledge group $(\mathrm{P}<0.001)$.

Significant factors were subjected to the backward binary logistic regression model and results showed that age, work, or education related to the medical field and marital status were predictors of a good knowledge score (Table 3). Respondents older than 30 years were 2.26 times more likely to have good knowledge as compared to participants 30 years old or less $(\mathrm{OR}=2.26, \mathrm{P}<0.001)$. Respondents working in the medical field were two times more likely to have good knowledge as compared to those not working in the medical field $(\mathrm{OR}=2.01, \mathrm{P}<0.001)$. Married respondents were also more likely to have good knowledge of DM as compared to single participants $(\mathrm{OR}=1.79, \mathrm{P}<0.001)$. Respondents with medical education were 1.88 times more likely to have good knowledge of $\mathrm{DM}$ as compared to those with non-medical education $(\mathrm{OR}=1.88, \mathrm{P}<$ $0.001)$ 


\section{Cureus}

\begin{tabular}{|c|c|c|c|c|c|}
\hline & \multicolumn{3}{|l|}{ Univariate analysis } & \multicolumn{2}{|c|}{ Multivariate analysis } \\
\hline & Poor/Moderate N=2369 & High $\mathbf{N}=839$ & $P$ & OR $[95 \% \mathrm{CI}]$ & $\mathbf{P}$ \\
\hline Gender: & & & $<0.001$ & ---- & --- \\
\hline Female & $1318(55.6 \%)$ & $382(45.5 \%)$ & & & \\
\hline Male & $1051(44.4 \%)$ & $457(54.5 \%)$ & & & \\
\hline Age: & & & $<0.001$ & & \\
\hline 30 years or less & $1838(77.6 \%)$ & $435(51.8 \%)$ & & Ref & \\
\hline$>30$ years & $531(22.4 \%)$ & $404(48.2 \%)$ & & $2.26[1.75,2.93]$ & $<0.001$ \\
\hline Monthly income: & & & $<0.001$ & --- & --- \\
\hline 2000+ SAR & $1195(50.4 \%)$ & $284(33.8 \%)$ & & & \\
\hline$<2000$ SAR & $1174(49.6 \%)$ & $555(66.2 \%)$ & & & \\
\hline Working in the medical field & & & $<0.001$ & & \\
\hline No & $2232(94.2 \%)$ & $709(84.5 \%)$ & & Ref & \\
\hline Yes & $137(5.78 \%)$ & $130(15.5 \%)$ & & $2.01[1.42,2.87]$ & $<0.001$ \\
\hline Marital status: & & & $<0.001$ & & \\
\hline Single & $1745(73.7 \%)$ & $406(48.4 \%)$ & & Ref & \\
\hline Married & $575(24.3 \%)$ & $407(48.5 \%)$ & & $1.79[1.38 .2 .32]$ & $<0.001$ \\
\hline Divorced & $49(2.07 \%)$ & $26(3.10 \%)$ & & & \\
\hline Education: & & & $<0.001$ & ---- & --- \\
\hline High school or less & $724(30.6 \%)$ & $201(24.0 \%)$ & & & \\
\hline Bachelor degree or more & $1645(69.4 \%)$ & $638(76.0 \%)$ & & & \\
\hline Education related to the medical field: & & & $<0.001$ & & \\
\hline No & $2116(89.3 \%)$ & $668(79.6 \%)$ & & Ref & \\
\hline Yes & $253(10.7 \%)$ & $171(20.4 \%)$ & & $1.88[1.39,2.54]$ & $<0.001$ \\
\hline
\end{tabular}

TABLE 3: Association of socioeconomic factors with knowledge of DM

DM: diabetes mellitus

The attitudes of the respondents were assessed using seven questions. Participants with a score of $<4$ points were considered as having negative attitudes. The great majority of respondents did not know whether metformin could cause kidney damage $(n=2651,82.6 \%)$ and more than half did not know whether long-term drug use could cause organ failure $(n=2073,64.6 \%)$ and whether insulin could cause harmful effects $(n=$ 1836, 57.2\%). Approximately half of the participants $(n=1666,51.9 \%)$ thought that glucose can be controlled by having the right diet better than using medications. Only $10.3 \%$ and $9.4 \%$ believed that using alternative therapy and herbal remedies would be better at controlling blood glucose levels than using medications and diet, respectively. Results showed that only $26.8 \%(n=860)$ of participants had positive attitudes toward DM. Results showed a statistically significant positive correlation between knowledge score and attitude score ( $\mathrm{r}=0.42, \mathrm{P}<0.001$ using Pearson's correlation).

The univariate association of socioeconomic factors with the positive attitude score $(\geqslant 4)$ was assessed using the chi-square test of independence. There was a statistically significant association between all socioeconomic factors included and having a positive attitude regarding DM. 


\section{Cureus}

Females were more prevalent in the good knowledge group as compared to the poor/moderate group (57.2\% vs. $51.4 \%, \mathrm{P}<0.05)$. Participants older than 30 years were also more prevalent in the positive attitude group as compared to the negative attitude group ( $35.2 \%$ vs. $26.9 \%$, respectively, $\mathrm{P}<0.001)$. Participants working in the medical field were more prevalent in the positive attitude group as compared to the negative attitude group (16.6\% vs. $5.28 \%$, respectively, $\mathrm{P}<0.001)$. There was a statistically significant association between marital status and having a positive attitude towards DM $(\mathrm{P}<0.001)$. Education showed a statistically significant association with having a positive attitude and respondents that received education related to the medical field were also more prevalent in the positive attitude group $(\mathrm{P}<0.001)$.

The backward binary logistic regression analysis showed that age, work, or education related to the medical field and educational degree were predictors of a positive attitude towards DM (Table 4). Respondents older than 30 years old were 3.51 times more likely to have a positive attitude as compared to participants 30 years old or less ( $\mathrm{OR}=3.51)$. Respondents working in the medical field were two times more likely to have a positive attitude as compared to those not working in the medical field $(\mathrm{OR}=1.96)$. Participants with a bachelor's degree or more were more likely to have a positive attitude towards DM as compared to those who only completed high school or lower $(\mathrm{OR}=1.28)$. Respondents with a medical education were 1.88 times more likely to have a positive attitude towards DM as compared to those with a non-medical education $(\mathrm{OR}=$ $1.83)$. 


\section{Cureus}

\begin{tabular}{|c|c|c|c|c|c|}
\hline & \multicolumn{3}{|l|}{ Univariate analysis } & \multicolumn{2}{|c|}{ Multivariate analysis } \\
\hline & Negative $\mathbf{N}=2348$ & Positive $\mathbf{N}=860$ & $P$ & OR $[95 \%$ CI] & $P$ \\
\hline Gender: & & & 0.004 & --- & --- \\
\hline Female & $1208(51.4 \%)$ & $492(57.2 \%)$ & & & \\
\hline Male & $1140(48.6 \%)$ & $368(42.8 \%)$ & & & \\
\hline Age: & & & $<0.001$ & & \\
\hline 30 years or less & $1716(73.1 \%)$ & $557(64.8 \%)$ & & Ref & \\
\hline$>30$ years & $632(26.9 \%)$ & $303(35.2 \%)$ & & $3.51[2.96,4.18]$ & \\
\hline Monthly income: & & & $<0.001$ & --- & --- \\
\hline$<2000$ SAR & $1131(48.2 \%)$ & $348(40.5 \%)$ & & & \\
\hline 2000+ SAR & 1217 (51.8\%) & $512(59.5 \%)$ & & & \\
\hline Working in the medical field & & & $<0.001$ & & \\
\hline No & $2224(94.7 \%)$ & $717(83.4 \%)$ & & Ref & \\
\hline Yes & $124(5.28 \%)$ & $143(16.6 \%)$ & & $1.96[1.38,2.8]$ & \\
\hline Marital status: & & & $<0.001$ & --- & --- \\
\hline Single & $1618(68.9 \%)$ & $533(62.0 \%)$ & & & \\
\hline Married & $684(29.1 \%)$ & $298(34.7 \%)$ & & & \\
\hline Divorced & $46(1.96 \%)$ & $29(3.37 \%)$ & & & \\
\hline Education: & & & $<0.001$ & & \\
\hline High school or less & 736 (31.3\%) & $189(22.0 \%)$ & & Ref & \\
\hline Bachelor degree or more & $1612(68.7 \%)$ & $671(78.0 \%)$ & & $1.28[1.06,1.54]$ & \\
\hline Education related to the medical field: & & & $<0.001$ & & \\
\hline No & $2110(89.9 \%)$ & $674(78.4 \%)$ & & Ref & \\
\hline Yes & $238(10.1 \%)$ & $186(21.6 \%)$ & & $1.83[1.35,2.46]$ & \\
\hline
\end{tabular}

\section{TABLE 4: Association of socioeconomic factors with attitude to DM}

DM: diabetes mellitus

Results showed that $91.3 \%$ of the respondents stated that they would seek treatment if they or one of their family members got DM. Approximately $50 \%$ of the participants (49.9\%) exercised regularly. More than half (68\%) of the respondents had never checked their blood glucose levels on an annual basis. More than half of the respondents (55.9\%) tried to avoid refined sugar (Figure 1). Univariate and multivariate analyses were performed to assess the association of socioeconomic factors with checking blood sugar regularly. 


\section{Cureus}

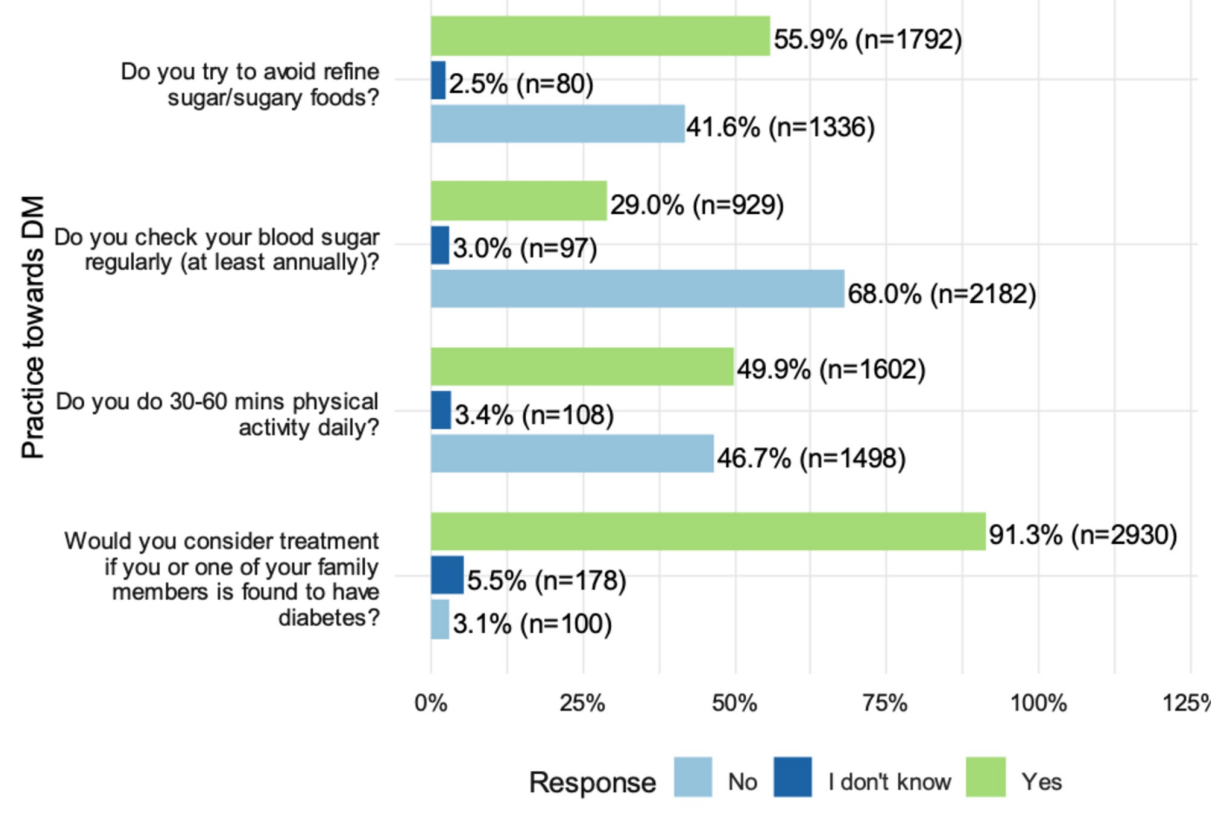

\section{FIGURE 1: Participants' responses to practice questions}

The univariate association of socioeconomic factors related to checking blood sugar regularly was assessed using the chi-square test of independence. Male gender, older age, working in the medical field, and marital status were significantly associated with checking blood glucose regularly. A higher monthly income also showed a statistically significant association with checking blood glucose at least annually.

A backward binary logistic regression analysis showed that age, monthly income, and working in the medical field were predictors of checking blood sugar at least annually (Table 5). Respondents older than 30 years old were 3.31 times more likely to check their blood glucose annually or less as compared to participants 30 years old or less $(\mathrm{OR}=3.31, \mathrm{P}<0.001)$. Respondents working in the medical field were 1.5 times more likely to check their blood glucose annually or less as compared to those not working in the medical field $(\mathrm{OR}=1.96, \mathrm{P}<0.001)$. Respondents with monthly income $2000+$ SAR were more likely to check their blood glucose annually or less as compared to those with average monthly income $<2000 \mathrm{SAR}$ (OR $=$ $1.43, \mathrm{P}<0.001)$. 


\section{Cureus}

\begin{tabular}{|c|c|c|c|c|c|}
\hline & \multicolumn{3}{|l|}{ Univariate analysis } & \multicolumn{2}{|c|}{ Multivariate analysis } \\
\hline & $>$ Annual $\mathrm{N}=\mathbf{2 2 7 9}$ & Annual or less $\mathrm{N}=929$ & $\mathbf{P}$ & OR $[95 \% \mathrm{Cl}]$ & $\mathbf{P}$ \\
\hline Gender: & & & $<0.001$ & --- & -- \\
\hline Female & $1315(57.7 \%)$ & $385(41.4 \%)$ & & & \\
\hline Male & $964(42.3 \%)$ & $544(58.6 \%)$ & & & \\
\hline Age: & & & $<0.001$ & & \\
\hline 30 years or less & $1811(79.5 \%)$ & $462(49.7 \%)$ & & Ref & \\
\hline$>30$ years & $468(20.5 \%)$ & $467(50.3 \%)$ & & $3.31[2.75,3.98]$ & $<0.001$ \\
\hline Monthly income: & & & $<0.001$ & & \\
\hline$<2000$ SAR & $1193(52.3 \%)$ & $286(30.8 \%)$ & & Ref & \\
\hline $2000+$ SAR & $1086(47.7 \%)$ & $643(69.2 \%)$ & & $1.43[1.19,1.72]$ & $<0.001$ \\
\hline Working in the medical field & & & 0.003 & & \\
\hline No & $2111(92.6 \%)$ & $830(89.3 \%)$ & & Ref & \\
\hline Yes & $168(7.37 \%)$ & $99(10.7 \%)$ & & $1.49[1.13,1.96]$ & $<0.001$ \\
\hline Marital status: & & & $<0.001$ & --- & --- \\
\hline Single & $1693(74.3 \%)$ & $458(49.3 \%)$ & & & \\
\hline Married & $540(23.7 \%)$ & $442(47.6 \%)$ & & & \\
\hline Divorced & $46(2.02 \%)$ & $29(3.12 \%)$ & & & \\
\hline Education: & & & 1.000 & ---- & --- \\
\hline High school or less & $657(28.8 \%)$ & $268(28.8 \%)$ & & & \\
\hline Bachelor degree or more & $1622(71.2 \%)$ & $661(71.2 \%)$ & & & \\
\hline Education related to the medical field: & & & 0.1 & ---- & --- \\
\hline No & $1993(87.5 \%)$ & $791(85.1 \%)$ & & & \\
\hline Yes & $286(12.5 \%)$ & $138(14.9 \%)$ & & & \\
\hline
\end{tabular}

TABLE 5: Association of socioeconomic factors with checking blood sugar regularly

The average knowledge score (Table 6 ) was higher across participants with better practice toward DM as compared to those with poor practices $(\mathrm{P}<0.001)$. 


\section{Cureus}

\begin{tabular}{|c|c|c|}
\hline & Knowledge Mean (SD) & $\mathbf{P}$ \\
\hline Consider treatment if you or one of your family members is found to have diabetes? & & $<0.001$ \\
\hline No & $13.1(4.96)$ & \\
\hline Yes & $15.9(3.78)$ & \\
\hline Regular physical activity & & $<0.001$ \\
\hline No & $15.3(4.18)$ & \\
\hline Yes & $16.1(3.73)$ & \\
\hline Check blood sugar regularly & & $<0.001$ \\
\hline No & $14.9(3.91)$ & \\
\hline Yes & $17.5(3.50)$ & \\
\hline Avoid refine sugar/sugary foods? & & 0.003 \\
\hline No & $14.9(4.06)$ & \\
\hline Yes & $16.3(3.81)$ & \\
\hline Statistical analysis was performed using unpaired t-tes & & \\
\hline
\end{tabular}

TABLE 6: Knowledge score among respondents with positive and negative practices toward DM DM: diabetes mellitus

\section{Discussion}

In the Eastern Mediterranean region, the prevalence of diabetes reaches 14\% [5]. Saudi Arabia is reported by WHO to rank the second in the Middle East and the seventh worldwide in terms of rate of diabetes [2]. This high prevalence and the associated comorbidities and burdens make it vital for health caregivers to establish prevention and management plans for diabetes. Knowledge, attitudes, and practice studies on the targeted population is the cornerstone for these prevention and management plans.

In this study, we are measuring knowledge in the whole population, a precise comparison of the knowledge results to others might be difficult because most of the other studies measure knowledge in diabetic patients (different targeted population) [6-7].

The average knowledge score for participants was $15.7 \pm 3.98$. About $53.5 \%$ of participants had good knowledge scores, which, as compared to a Jordanian study $(17.9 \pm 4.14)$ [4], is approximately the same, with moderate and good levels of knowledge. This suggests that the knowledge of DM in Saudi society is good, and further prevention plans from the government would not face major obstacles.

This study reports that in the management of DM, the majority of the population ( $85.5 \%$ and $49.2 \%)$ were aware that insulin injections and oral medications, respectively, were effective for DM. At the minimum, participants thought that using insulin could be harmful and the long use of oral hypoglycemic causes organ failure (17.1\% and $18 \%$, respectively). However, the study conducted in Jordan showed that $34.7 \%$ and $40 \%$ of the population thought that insulin is harmful and oral hypoglycemics cause renal damage respectively [4]. In addition, a study from Sri Lanka found that $20 \%$ of their participants believe that the long-term use of insulin is harmful [8].

This may suggest that the awareness of DM medications in our participants meets expectations.

A very alarming and significant portion of the participants (32.2\%) reported that the use of complementary and alternative medicine (CAM) like ginger and cinnamon might achieve glycemic control while. Where other Gulf countries, such as Bahrain, showed an even higher number (63\%) [9], a study in Jordan showed a lower percentage (16\%) [4]. Without any medical supervision, the use of CAM in the management of diabetes can be very dangerous and may lead to many complications. But thankfully, $10.3 \%$ agreed that CAM medicine is better than the prescribed methods. Still, the degree of really knowing the percentage of using CAM is anonymous because the patients' disclosure of CAM usage is unknown. Encouraging patients to unveil the usage of CAM, as well as the awareness and education of society about CAM in managing diabetes and other chronic diseases, is very fundamental in management and prevention strategies. 
More than half (68\%) of the respondents had never checked their blood glucose level on an annual basis, which is more than a study from Sri Lanka (50\%) [8]. This may raise an alarm that awareness of diabetes screening is crucial. As the disease progresses, more complications and burdens appear. Picking up the disease early surely impacts the patient's quality of life, prevents complications, and is cost-effective.

The limitation of this study includes the cross-sectional nature of this study in addition to the possibility of response bias and the result might not be representative of the general population; however, our study can be useful to those who are involved in health education and promotion.

\section{Conclusions}

In conclusion, our study shows that the majority of the participants had never checked their blood glucose levels. In addition, one-third of the participants believed that the use of complementary medicine could actually control diabetes.

\section{Additional Information \\ Disclosures}

Human subjects: Consent was obtained by all participants in this study. Animal subjects: All authors have confirmed that this study did not involve animal subjects or tissue. Conflicts of interest: In compliance with the ICMJE uniform disclosure form, all authors declare the following: Payment/services info: All authors have declared that no financial support was received from any organization for the submitted work. Financial relationships: All authors have declared that they have no financial relationships at present or within the previous three years with any organizations that might have an interest in the submitted work. Other relationships: All authors have declared that there are no other relationships or activities that could appear to have influenced the submitted work.

\section{References}

1. World Health Organization. Diabetes. (2018). Accessed: December 2019: https://www.who.int/newsroom/fact-sheets/detail/diabetes.

2. Al Dawish MA, Alwin Robert AA, Braham R, Al Hayek AA, Al Saeed A, Ahmed RA, Al Sabaan FS: Diabetes mellitus in Saudi Arabia: a review of the recent literature. Curr Diabetes Rev. 2016, 12:359-368. 10.2174/1573399811666150724095130

3. Atkinson MA, Maclaren NK: The pathogenesis of insulin dependent diabetes . N Engl J Med. 1994, 331:14281436. 10.1056/NEJM199411243312107

4. Alsous M, Jalil MA, Odeh M, Al Kurdi R, Alnan M: Public knowledge, attitudes and practices toward diabetes mellitus: a cross-sectional study from Jordan. PloS One. 2019, 14:e0214479. 10.1371/journal.pone.0214479

5. World Health Organization: Global Status Report on Non-communicable Diseases 2014 . World Health Organization, Geneva, Switzerland; 2014.

6. Al-Maskari F, El-Sadig M, Al-Kaabi JM, Afandi B, Nagelkerke N, Yeatts KB: Knowledge, attitude and practices of diabetic patients in the United Arab Emirates. PloS One. 2013, 2013:0052857. 10.1371/journal.pone.0052857

7. Niroomand M, Ghasemi SN, Karimi-Sari H, Kazempour-Ardebili S, Amiri P, Khosravi MH: Diabetes knowledge, attitude and practice (KAP) study among Iranian in-patients with type-2 diabetes: a crosssectional study. Diabetes Metab Syndr. 2016, 10:S114-S119. 10.1016/j.dsx.2015.10.006

8. Herath HMM, Weerasinghe NP, Dias H, Weerarathna TP: Knowledge, attitude and practice related to diabetes mellitus among the general public in Galle district in Southern Sri Lanka: a pilot study. BMC Public Health. 2017, 17:535. 10.1186/s12889-017-4459-5

9. Khalaf AJ, Whitford DL: The use of complementary and alternative medicine by patients with diabetes mellitus in Bahrain: a cross-sectional study. BMC Complem Altern Med. 2010, 10:35. 10.1186/1472-6882-1035 